The Journal of Animal \& Plant Sciences, 30(3): 2020, Page: 677-684

ISSN (print): 1018-7081; ISSN (online): 2309-8694

\title{
ADDITIVE MAIN EFFECT AND MULTIPLICATIVE INTERACTION ANALYSIS FOR GRAIN YIELD IN BREAD WHEAT
}

\author{
M. A. U. Khan' ${ }^{1}$, F. Mohammad ${ }^{1}$, F. U. Khan², S. Ahmad ${ }^{1}$ and I. Ullah ${ }^{3}$ \\ ${ }^{1}$ Department of Plant Breeding \& Genetics, The University of Agriculture Peshawar, Pakistan \\ ${ }^{2}$ Department of Agriculture, Hazara University Dodhial Mansehra, Pakistan \\ ${ }^{3}$ Department of Genetics, Hazara University Dodhial Mansehra, Pakistan \\ Corresponding author's email: fahimbiotech@gmail.com
}

\begin{abstract}
Testing breeding material in diverse environments is required for cultivar development to curtail cross over interaction. Seventy-nine bread wheat Recombinant Inbred Lines (RIL's) along with two check cultivars were field-tested across nine environments (sites $\times$ year network) in Khyber Pakhtunkhwa, Pakistan using alpha lattice design with two replicates during 2013/16. Combined analysis of variance revealed significant differences among genotypes, environments and genotype by interactions (GEI) for grain yield. The AMMI analysis revealed a major role of GEI (72.4\%) in total phenotypic expression of grain yield. Larger variation due to GEI indicated that both performance and ranking of genotypes were fluctuated mainly due to the interaction of genotypes with environments. Environment and genotypes had almost equal contributions to the total sum of squares. Sum of squares due to GEI was 5 times larger than that for genotypes, suggesting the existence of mega environments. Similarly, smaller sum of squares due to environments and genotypes indicated minor contribution towards total variation. Conversely, larger GEI sum of squares implies unstable performance and the existence of cross over interactions between genotypes and environments for all studied traits. AMMI analysis partitioned GEI sum of squares into eight principal components for the studied traits. The first two principal components (PC1 and PC2) explained half of the total GEI sum of squares, thus sufficient to explain the complex patterns of GE interaction for studied traits. The AMMI1 model identified G-79 as the most stable and high yielding genotype for grain yield. Similarly, AMMI2 biplot revealed G-58 as widely adaptable genotype for grain yield Among environments, E-02 and E-07 were the highest and lowest productive environments for grain yield. AMMI analysis identified G-79 as the most stable and high yielding RILs and thus, recommended for extensive testing.
\end{abstract}

Keywords: G×E interaction; Genotypes; Multi-environment trial; Recombinant Inbred Lines; Stability. https://doi.org/10.36899/JAPS.2020.3.0080 Published online March 25, 2020

\section{INTRODUCTION}

Sporadic and parched environments can impend danger to crop production. Unpredictable patterns of precipitation and fluctuation in temperature across years can dramatically change phenotypes of seasonal crops. Such changes in performance usually lead to cross over interaction which restricts a variety to a specific locality. Therefore, plant breeders test their breeding material in multi-environment trials (METs) to identify stable and widely adapted genotypes. Differential response of genotypes to environments depends upon the magnitude of the interactions. Routine analysis of variance (ANOVA) can quantify main effects but it is ineffective to give insights into complex patterns of GE interaction. Therefore, other statistical method such as the Additive Main Effect and Multiplicative Interaction (AMMI) is valuable in explaining a large part of GEI (Gauch and Zobel, 1997).

AMMI analysis is a hybrid method that combines analysis of variance (ANOVA) and principal components analysis (PCA) to analyze data of multi- environment trials (Gauch, 1992). Most of the researchers supported the use of AMMI analysis for multivariate study (Gauch and Zobel, 1997; Ferreira et al., 2006). Comparison of AMMI analysis with simple ANOVA and regression analysis revealed that ANOVA failed to describe significant interaction component, while the regression approach explained only a fraction of interaction sum of squares (Gauch and Zobel, 1997). Conversely, PCA failed to identify main effects of genotypes and environments. Hence, AMMI analysis has proved to be an effective technique to gain insights into complexity of GEI.

The scores of PCs can be drawn into useful biplots for visual inspection of GEI. The angle between genotypes and environmental vectors shows the degree of association between environments or genotypes. The interaction of genotypes with environments would be positive if the angle is less than $90^{\circ}$ or larger than $270^{\circ}$. Similarly, the association would be negative when the angle is between $90^{\circ}$ and $270^{\circ}$. The genotypes lying closer to the origin are considered stable and widely adapted, whereas genotypes lying far away from the origin are considered as sensitive and specifically 
adapted. Similarly, cosine of angle between two vectors of environments or genotypes gives a sign of phenotypic correlation between two genotypes or environments i.e. smaller the angle closer the relationship.

In the current study, 79 wheat RILs along with two check cultivars were field-tested across nine environments for yield and other production traits to; i) interpret GEI obtained by AMMI analysis of yield and associated traits, (ii) assess yield performance of genotypes across environments based on the AMMI biplots, and (iii) identify high yielding and relatively stable genotypes based on AMMI model for further extensive testing before commercialization.

\section{MATERIALS AND METHODS}

Seventy-nine wheat RILs along with two check cultivars were field-tested across nine environments during 2013/16 using Additive Main Effect and Multiplicative Interaction (AMMI) analysis. Detailed description of the experimental sites, history of breeding material, experimental designs and statistical analysis are given as under:

Description of experimental sites: Eighty-one genotypes including $79 \mathrm{~F}_{5: 8}$ RILs and two check cultivars "Janbaz" and "Atta-Habib" were evaluated in nine environments during 2013/14, 2014/15 and 2015/16. During 2013/14, the experimental material was planted at single location i.e. The University of Agriculture Peshawar (E-01) for evaluation and seed multiplication. Whereas, the experiments were planted during 2014/15 and 2015/16 at The University of Agriculture Peshawar (E-02 and E-03, respectively), Cereal Crops Research Institute, Pirsabak Nowshehra (E-04 and E-05, respectively), Agricultural Research Station, Charsadda (E-06 and E-07, respectively) and Agricultural Research Station, Swabi (E-08 and E-09, respectively). Hereafter, these will be referred as E-01, E-02, E-03, E-04, E-05, E06, E-07, E-08, and E-09. Agro-metrological features of test sites/environments including temperature, rainfalls etc. are given in Table 1.

Breeding history of plant material: Seventy-nine $F_{5: 8}$ RILs were originally developed in the department of Plant Breeding and Genetics during 2002/03 (Table 2). The segregating populations were advanced in bulk till $\mathrm{F}_{4}$ generation. In $\mathrm{F}_{5}$ generation, single heads were selected from the bulk populations based on agronomic fitness and disease resistance. The $\mathrm{F}_{5: 6}$ heads were raised as head-torow for seed multiplication and disease screening against stripe rust in particular. However, lines were found segregating for stripe rust resistance. Therefore, twenty heads were hand harvested and planted as head-to-row during 2012/13. The heavy infestation of stripe and leaf rusts fungi offered opportunity for screening $\mathrm{F}_{5: 7}$ RILs.
For the current study, $79 \mathrm{~F}_{5: 8}$ RILs were selected for further evaluation in multi-location trials over years.

Experimental design and procedure: Eighty-one genotypes including $79 \mathrm{~F}_{5: 8}$ RILs and two check cultivars (Janbaz and Atta-Habib) were field-tested in nine environments during 2013/14, 2014/15 and 2015/16. List of genotypes with parentage is given in Table 2 . Experimental material was planted in $9 \times 9$ alpha lattice design with two replicates at each environment. Each plot had 6 rows of 5-meter length and a row-to-row space of $30 \mathrm{~cm}$. Standard dose of nitrogen $\left(120 \mathrm{~kg} \mathrm{ha}^{-1}\right)$ and phosphorous (80 $\mathrm{kg} \mathrm{ha}^{-1}$ ) was applied. Uniform cultural practices required for wheat crop were followed throughout the growing season.

Additive Main Effect and Multiplicative Interaction (AMMI) analysis: Additive Main effect and Multiplicative Interaction (AMMI) analysis for grain yield was carried out using GEA-R version 4.0 (GEA-R, 2015) computer software (Pacheco et al., 2015). AMMI biplots were constructed based on PC1, PC2 scores and mean grain yield. Each location over years was considered as independent environment.

The AMMI model for genotypes and environments is given as;

$$
\mathrm{Yij}=\mu+G_{i}+E_{j}+\sum_{k=1}^{\eta} \lambda_{k} \alpha_{i k} \gamma_{j k}+\varepsilon_{i j}
$$

AMMI stability value: The ranking of genotypes based on their stability was computed following Purchaseet al. (2000).

$$
A S V=\sqrt{\left[\frac{S S_{I P C A 1}}{S S_{I P C A 2}}(I P C A 1 \text { Scor } 8)\right]^{2}+(\text { IPCA2 Score })^{2}}
$$

Where $\mathrm{SS}_{\text {IPCA1}} / \mathrm{SS}_{\text {IPCA2 } 2}$ is the weight given to the IPCA1 value by dividing the IPCA1 sum of squares by the IPCA2 sum of squares.

\section{RESULTS}

The AMMI analysis (Table 3) for grain yield revealed significant $(\mathrm{P} \leq 0.01) \quad$ differences among genotypes, environments and their interactions (GEI). The AMMI model specified that GEI explained $72.4 \%$ variation in the total sum of squares whereas, environments and genotypes captured $18.1 \%$ and $9.6 \%$ variation, respectively. The larger sum of squares due to GEI indicated response of genotypes to varied environments. In the total variation, substantial contribution of GEI suggested different sets of high yielding genotypes and the existence of potential megaenvironments (Gauch and Zobel, 1996). The GEI sum of squares was subdivided into eight-interaction principal components axis (IPCA). The first seven principal components were highly significant and cumulatively explained $99.2 \%$ of the variation. However, the first two 
principal components $(\mathrm{PC} 1=35.8 \%$ and $\mathrm{PC} 2=19.0 \%)$ explained $54.8 \%$ of GEI sum of squares, and thus, were adequate to extract meaningful information.

Mean yield of nine environments were plotted against the scores of first principal component (PC1) to examine visually the genotypic response to varying environments (Fig. 1). It is clear from the Figure 1 that E02 was the most productive environment in terms of grain yield followed by E-03, E-06 and E-07. Environments E01 and E-07 appeared as most stable causing least fluctuations in the yield performance of the tested genotypes due to their proximity to $\mathrm{x}$-axis. Environments E-04 and E-08 were the most discriminating as specified by their long distances from the $\mathrm{x}$-axis. Among genotypes, G-79 was the most stable and produced maximum grain yield (Fig. 1).

The AMMI2 model was better than AMMI1 because the first two principal components (IPCA1 and IPCA2) explained $54.8 \%$ of the GEI (Fig. 2). Likewise, by plotting IPCA2 and IPCA3 scores AMMI3 biplot could be used, however higher axes are dominated by noise and have little predictive value (Purchase et al., 2000). For each genotype, the magnitude of principal component scores indicated the stability of that genotype over environments. Genotypes which have higher score of IPCA indicated inconsistency and hence, such genotypes are specifically adapted to a particular environment. Genotypes G-11, G-18, G-28, G-52 and G58 appeared as widely adaptable to diverse environments due to their position in the proximity of origin (Fig. 2).
Nine environmental vectors representing nine environments were spread over four quadrants. Vectors sharing the same quadrant indicated similar response of genotypes towards that particular environment(s). Likewise, the widespread of genotypes in all quadrants showed the overall inconsistency of genotypes across the tested environments. The long vector of E-05 showed its high discriminating power. In contrast, environments E01, E-02, E-03, E-06, E-07 and E-09 had shortest vectors indicating their low discriminating power. In other words, these environments exerted less force on genotypes to deviate from mean yield Similarly, genotypes exhibited superior performance in particular environment indicated their specific adaptation. Genotypes lying close with environment vectors showed that these genotypes had specific adaptation to these environments like G-01 to E01, G-05 to E-02, G-26 to E-07 and G-72 to E-03 and E06 (Fig. 1).

AMMI stability value (ASV) and ranking of genotypes based on ASV are given in Table 4. Genotypes G-14 (0.14), G-81 (0.14), G-52 (0.14) and G-32 (0.15) had lower ASV and thus, were relatively stable. Contrarily, G-51 (1.83), G-41 (1.81) and G-30 (1.71) were the most unstable genotypes as evident from their larger ASV. Genotype G-79 had high mean grain yield $\left(4861.8 \mathrm{~kg} \mathrm{ha}^{-1}\right)$ with relatively low ASV $(0.37)$ could be declared as high yielding and stable genotype. Likewise, lower values for grain yield and ASV for G-11 (3054.1 and 0.23), G-21 (2872.7 and 0.34) and G-67 (3101.4 and 0.50 ) implied that these genotypes repeatedly produced low grain yield in all the tested environments.

Table 1. Description of nine environments used for evaluation of 81 wheat genotypes during 2014-2016 cropping season.

\begin{tabular}{|c|c|c|c|c|c|c|c|}
\hline \multirow[t]{2}{*}{ Environments } & \multirow{2}{*}{$\begin{array}{c}\text { Growing } \\
\text { season }\end{array}$} & \multicolumn{2}{|c|}{ Geographical Position } & \multirow{2}{*}{$\begin{array}{l}\text { Altitude } \\
\text { (m.a.s.l) }\end{array}$} & \multirow{2}{*}{$\begin{array}{l}\text { Average rainfall } \\
\text { (mm) }\end{array}$} & \multicolumn{2}{|c|}{ Temperature $\left({ }^{0} \mathrm{c}\right)$} \\
\hline & & Latitude & Longitude & & & Min. & Max. \\
\hline E1 & 2014 (AUP) & $34.0150^{\circ} \mathrm{N}$ & $71.5805^{\circ} \mathrm{E}$ & 359 & 238 & 20.1 & 34.8 \\
\hline E2 & 2015 (AUP) & --do-- & --do-- & --do-- & 415 & 19.5 & 35.4 \\
\hline E3 & 2016 (AUP) & --do-- & --do-- & --do-- & 189 & 17.8 & 38.2 \\
\hline E4 & 2015 (CCRI) & $34.0159^{\circ} \mathrm{N}$ & $71.9755^{\circ} \mathrm{E}$ & 288 & 220 & 10.1 & 28.6 \\
\hline E5 & 2016 (CCRI) & --do-- & --do-- & --do-- & 112 & 16.3 & 35.9 \\
\hline E6 & 2015 (ARSS) & $34.1442^{\circ} \mathrm{N}$ & $72.3785^{\circ} \mathrm{E}$ & 321 & 263 & 18.0 & 36.7 \\
\hline E7 & 2016 (ARSS) & --do-- & --do-- & --do-- & 312 & 14.5 & 32.1 \\
\hline E8 & 2015 (ARSC) & $34.1494^{\circ} \mathrm{N}$ & $71.7428^{\circ} \mathrm{E}$ & 381 & 460 & 10.4 & 28.5 \\
\hline E9 & 2016 (ARSC) & --do-- & --do-- & --do-- & 392 & 17.4 & 36.2 \\
\hline
\end{tabular}

Source: Meteorological Department, Khyber Pakhtunkhwa, Pakistan

Note: AUP= Agriculture University of Peshawar; CCRI= Cereal Crops Research Institute, Pirsabak; ARSS= Agricultural Research Station Sawabi and ARSC $=$ Agricultural Research Station Charssadda

Table 2.List of wheat RILs with pedigree.

\begin{tabular}{llll}
\hline Code & Pedigree & Code & Pedigree \\
\hline G-01 & Takbir $\times$ Khatakwal-3-1 & G-42 & Tatara $\times$ Inqilab-26-7 \\
G-02 & Takbir $\times$ Khatakwal-3-5 & G-43 & Tatara $\times$ Inqilab-26-11 \\
G-03 & Takbir $\times$ Khatakwal-3-7 & G-44 & Tatara $\times$ Inqilab-26-15 \\
\hline
\end{tabular}




\begin{tabular}{|c|c|c|c|}
\hline G-04 & Takbir $\times$ Khatakwal-3-8 & G-45 & Tatara $\times$ Inqilab-26-20 \\
\hline G-05 & Takbir $\times$ Khatakwal-3-9 & G-46 & Tatara $\times$ Ghaznavi 98-31-1 \\
\hline G-06 & Takbir $\times$ Khatakwal-3-16 & G-47 & Tatara $\times$ Ghaznavi 98-31-2 \\
\hline G-07 & Takbir $\times$ Khatakwal-3-18 & G-48 & Tatara $\times$ Ghaznavi 98-31-4 \\
\hline G-08 & Tatara $\times$ Inqilab-4-3 & G-49 & Tatara $\times$ Ghaznavi 98-31-7 \\
\hline G-09 & Tatara $\times$ Inqilab-4-6 & G-50 & Ghaznavi $98 \times$ Khatakwal $-33-5$ \\
\hline G-10 & Tatara $\times$ Inqilab-4-9 & G-51 & Ghaznavi $98 \times$ Khatakwal -33-7 \\
\hline G-11 & Tatara $\times$ Inqilab-4-10 & G-52 & Ghaznavi $98 \times$ Khatakwal $-33-10$ \\
\hline G-12 & Tatara $\times$ Inqilab-4-11 & $\mathrm{G}-53$ & Ghaznavi $98 \times$ Khatakwal $-33-15$ \\
\hline G-13 & Tatara $\times$ Inqilab-4-13 & G-54 & Tatara $\times$ Ghaznavi 98-37-15 \\
\hline G-14 & Tatara $\times$ Inqilab-4-16 & G-55 & Tatara $\times$ Margala-43-2 \\
\hline G-15 & Wafaq $\times$ Ghaznavi 98 & G-56 & Tatara $\times$ Margala-43-4 \\
\hline G-16 & Wafaq $\times$ Ghaznavi 98 & $\mathrm{G}-57$ & Tatara $\times$ Margala-43-11 \\
\hline G-17 & Wafaq $\times$ Ghaznavi 98 & G-58 & Tatara $\times$ Margala-43-12 \\
\hline G-18 & Tatara $\times$ Takbir-9-8 & G-59 & Tatara $\times$ Inqilab $-45-10$ \\
\hline G-19 & Tatara $\times$ Takbir-9-10 & G-60 & Takbir $\times$ Inqilab $-45-12$ \\
\hline G-20 & Tatara $\times$ Takbir-9-12 & G-61 & Tatara $\times$ Ghaznavi 98-48-2 \\
\hline G-21 & Tatara $\times$ Takbir-9-813 & G-62 & Tatara $\times$ Ghaznavi 98-48-3 \\
\hline G-22 & Tatara $\times$ Inqilab-18-15 & G-63 & Tatara $\times$ Ghaznavi 98-48-13 \\
\hline G-23 & Tatara $\times$ Inqilab-18-19 & G-64 & Tatara $\times$ Ghaznavi $98-48-15$ \\
\hline G-24 & Tatara $\times$ Inqilab-18-20 & G-65 & Tatara $\times$ Ghaznavi 98-48-19 \\
\hline G-25 & Tatara × Takbir-19-3 & G-66 & Wafaq $\times$ Ghaznavi 98-49-2 \\
\hline G-26 & Tatara $\times$ Takbir-19-4 & G-67 & Wafaq $\times$ Ghaznavi 98-49-4 \\
\hline G-27 & Tatara $\times$ Takbir-19-8 & G-68 & Wafaq $\times$ Ghaznavi 98-49-5 \\
\hline G-28 & Tatara $\times$ Takbir-19-11 & G-69 & Wafaq $\times$ Ghaznavi 98-49-6 \\
\hline G-29 & Tatara $\times$ Takbir-19-16 & G-70 & Wafaq $\times$ Ghaznavi 98-49-9 \\
\hline G-30 & Tatara $\times$ Takbir-19-18 & G-71 & Wafaq $\times$ Ghaznavi 98-49-10 \\
\hline G-31 & Tatara $\times$ Ghaznavi 98-22-1 & $\mathrm{G}-72$ & Wafaq $\times$ Ghaznavi 98-49-12 \\
\hline G-32 & Tatara $\times$ Ghaznavi 98-22-2 & G-73 & Wafaq $\times$ Ghaznavi 98-49-13 \\
\hline G-33 & Tatara $\times$ Ghaznavi 98-22-6 & G-74 & Wafaq $\times$ Ghaznavi 98-49-15 \\
\hline G-34 & Tatara $\times$ Ghaznavi 98-22-8 & G-75 & Wafaq $\times$ Ghaznavi 98-49-16 \\
\hline G-35 & Tatara $\times$ Ghaznavi 98-22-9 & $\mathrm{G}-76$ & Wafaq $\times$ Ghaznavi 98-49-19 \\
\hline G-36 & Tatara $\times$ Ghaznavi 98-22-12 & G-77 & Wafaq $\times$ Ghaznavi 98-49-20 \\
\hline G-37 & Tatara $\times$ Ghaznavi 98-22-13 & G-78 & Tatara $\times$ Takbir-19-17 \\
\hline G-38 & Tatara $\times$ Ghaznavi 98-22-19 & G-79 & Tatara $\times$ Takbir-19-18 \\
\hline G-39 & Tatara $\times$ Ghaznavi 98-22-20 & Check & Janbaz \\
\hline G-40 & Tatara $\times$ Inqilab-26-4 & Check & Atta-Habib \\
\hline G-41 & Tatara $\times$ Inqilab-26-6 & & \\
\hline
\end{tabular}

Table 3. AMMI analysis of variance for grain yield in bread wheat.

\begin{tabular}{ccccc}
\hline Source & Df & SS & MS & Proportion (\%) \\
\hline Total & 728 & 711964567 & - & - \\
Genotypes & 80 & 128592752 & $1607409^{* *}$ & 9.6 \\
Environments & 8 & 68248278 & $8531035^{* *}$ & 18.1 \\
G×E & 640 & 515123537 & $804881^{* *}$ & 72.4 \\
PC1 & 87 & 184350264 & $2118969^{* *}$ & 35.8 \\
PC2 & 85 & 97697663 & $1149384^{* *}$ & 19.0 \\
PC3 & 83 & 62119429 & $748427^{* *}$ & 12.1 \\
PC4 & 81 & 57610655 & $711243^{* *}$ & 11.2 \\
PC5 & 79 & 36715919 & $591341^{* *}$ & 9.1 \\
PC6 & 77 & 29697903 & $422051^{* *}$ & 6.3 \\
PC7 & 75 & 4513848 & $394905^{* *}$ & 5.7 \\
PC8 & 73 & $61834^{\text {ns }}$ & 0.9 \\
Residuals & 729 & 232277 & - \\
\hline
\end{tabular}

${ }^{*}$ and ${ }^{* *}$ shows significant at 5 and $1 \%$ levels of probability, whereas ns shows non-significant 
Table 4. Ranking of genotypes based on ASV(AMMI stability value) and mean performance of grain yield.

\begin{tabular}{|c|c|c|c|c|c|c|c|c|c|}
\hline Geno. & Mean & Rank & ASV & Rank & Geno. & Mean & Rank & ASV & Rank \\
\hline G-01 & 3580.6 & 22 & 0.38 & 18 & G-42 & 3206.8 & 68 & 0.76 & 43 \\
\hline G-02 & 3377.7 & 42 & 0.72 & 40 & G-43 & 3588.1 & 21 & 1.05 & 68 \\
\hline G-03 & 3441.0 & 33 & 1.47 & 77 & G-44 & 3156.4 & 71 & 1.01 & 64 \\
\hline G-04 & 3239.1 & 65 & 0.48 & 26 & G-45 & 3612.4 & 17 & 0.27 & 9 \\
\hline G-05 & 3843.8 & 7 & 0.86 & 54 & G-46 & 3490.2 & 29 & 0.93 & 59 \\
\hline G-06 & 3405.4 & 37 & 1.02 & 65 & G-47 & 3111.3 & 76 & 0.62 & 31 \\
\hline G-07 & 3715.5 & 11 & 0.23 & 8 & G-48 & 3391.2 & 40 & 0.93 & 58 \\
\hline G-08 & 4194.9 & 2 & 1.35 & 72 & G-49 & 3356.2 & 47 & 0.82 & 52 \\
\hline G-09 & 3263.9 & 59 & 0.63 & 33 & G-50 & 3506.3 & 27 & 0.43 & 22 \\
\hline G-10 & 3812.1 & 8 & 0.76 & 44 & G-51 & 3133.8 & 73 & 1.83 & 81 \\
\hline G-11 & 3054.1 & 79 & 0.23 & 7 & G-52 & 3314.9 & 51 & 0.14 & 3 \\
\hline G-12 & 3138.4 & 72 & 0.53 & 28 & G-53 & 3295.5 & 54 & 0.38 & 17 \\
\hline G-13 & 3280.6 & 57 & 0.77 & 45 & G-54 & 3622.5 & 15 & 1.33 & 71 \\
\hline G-14 & 3284.3 & 56 & 0.14 & 1 & G-55 & 3388.8 & 41 & 0.80 & 49 \\
\hline G-15 & 3354.0 & 48 & 0.29 & 11 & G-56 & 4030.0 & 3 & 0.92 & 57 \\
\hline G-16 & 3691.8 & 13 & 1.05 & 67 & G-57 & 3104.8 & 77 & 0.61 & 30 \\
\hline G-17 & 3222.1 & 67 & 0.43 & 21 & G-58 & 3391.9 & 39 & 0.35 & 14 \\
\hline G-18 & 3399.9 & 38 & 0.89 & 56 & G-59 & 3459.1 & 32 & 1.02 & 66 \\
\hline G-19 & 3901.3 & 5 & 1.62 & 78 & G-60 & 3366.1 & 44 & 1.18 & 69 \\
\hline G-20 & 3131.2 & 74 & 0.47 & 25 & G-61 & 3240.8 & 62 & 1.22 & 70 \\
\hline G-21 & 2872.7 & 80 & 0.34 & 13 & G-62 & 3419.0 & 35 & 0.79 & 48 \\
\hline G-22 & 3250.8 & 61 & 0.74 & 42 & G-63 & 3263.5 & 60 & 0.94 & 61 \\
\hline G-23 & 3361.6 & 45 & 1.45 & 76 & G-64 & 3544.2 & 26 & 0.43 & 23 \\
\hline G-24 & 3324.6 & 50 & 0.43 & 20 & G-65 & 3178.8 & 70 & 0.95 & 62 \\
\hline G-25 & 3589.4 & 20 & 1.40 & 73 & G-66 & 3693.3 & 12 & 0.42 & 19 \\
\hline G-26 & 3589.6 & 19 & 0.37 & 16 & G-67 & 3101.4 & 78 & 0.50 & 27 \\
\hline G-27 & 3467.5 & 31 & 0.79 & 46 & G-68 & 3429.4 & 34 & 1.44 & 75 \\
\hline G-28 & 3608.1 & 18 & 0.16 & 5 & G-69 & 3116.2 & 75 & 0.74 & 41 \\
\hline G-29 & 3273.5 & 58 & 0.63 & 34 & G-70 & 3678.2 & 14 & 0.30 & 12 \\
\hline G-30 & 3481.1 & 30 & 1.73 & 79 & G-71 & 3766.6 & 9 & 0.81 & 51 \\
\hline G-31 & 3556.2 & 23 & 0.68 & 37 & G-72 & 3553.9 & 24 & 0.65 & 36 \\
\hline G-32 & 3547.9 & 25 & 0.15 & 4 & G-73 & 3873.0 & 6 & 0.87 & 55 \\
\hline G-33 & 3408.9 & 36 & 0.82 & 53 & G-74 & 3349.3 & 49 & 0.63 & 32 \\
\hline G-34 & 3358.3 & 46 & 0.28 & 10 & G-75 & 3366.2 & 43 & 0.68 & 38 \\
\hline G-35 & 3614.9 & 16 & 0.65 & 35 & G-76 & 3225.0 & 66 & 0.94 & 60 \\
\hline G-36 & 3755.5 & 10 & 0.56 & 29 & G-77 & 3240.4 & 63 & 0.81 & 50 \\
\hline G-37 & 4003.1 & 4 & 1.42 & 74 & G-78 & 3206.1 & 69 & 0.95 & 63 \\
\hline G-38 & 3313.8 & 53 & 0.79 & 47 & G-79 & 4861.8 & 1 & 0.37 & 15 \\
\hline G-39 & 3314.6 & 52 & 0.47 & 24 & G- 80 & 3287.2 & 55 & 0.16 & 6 \\
\hline G-40 & 2803.5 & 81 & 0.68 & 39 & G-81 & 3239.7 & 64 & 0.14 & 2 \\
\hline G-41 & 3497.2 & 28 & 1.81 & 80 & Mean & 3438.1 & - & - & - \\
\hline
\end{tabular}




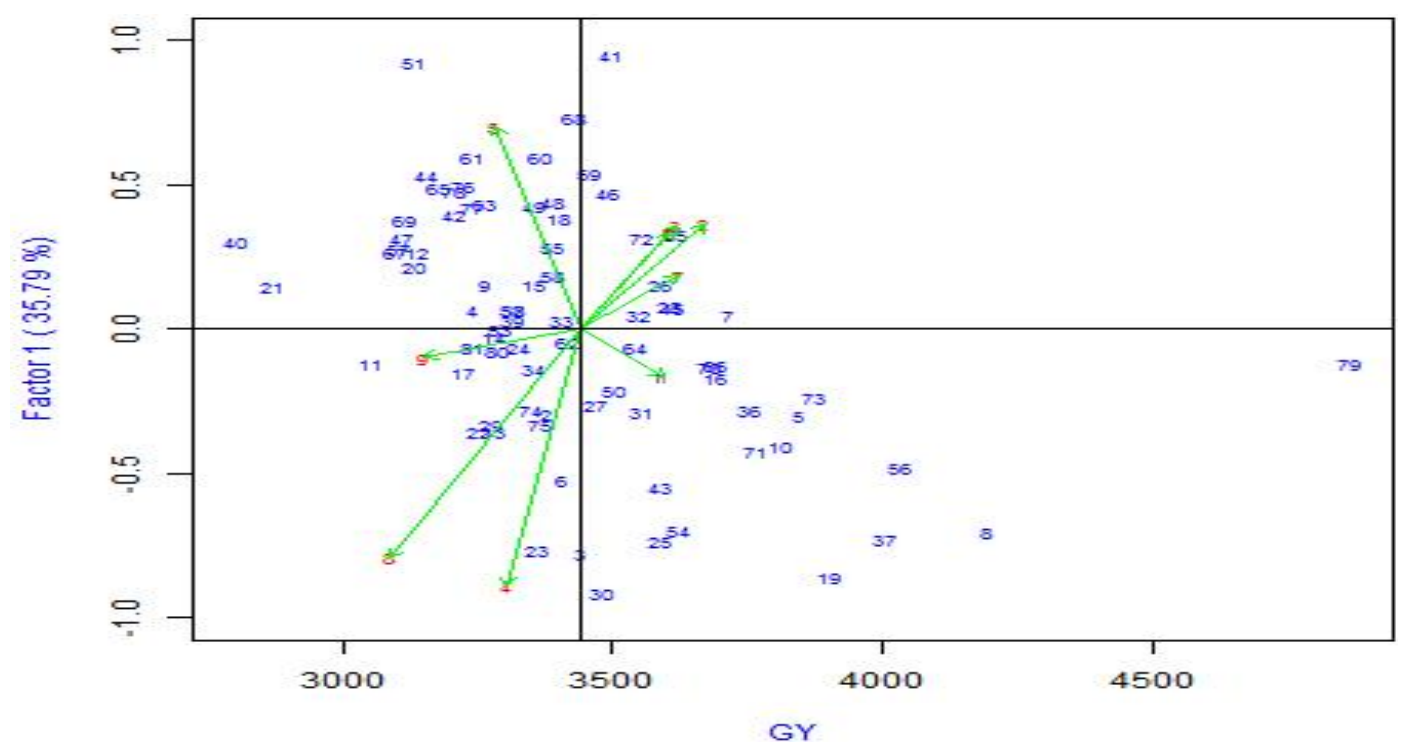

Fig 1. AMM1 biplot for grain yield of 81 wheat genotypes tested over nine environments

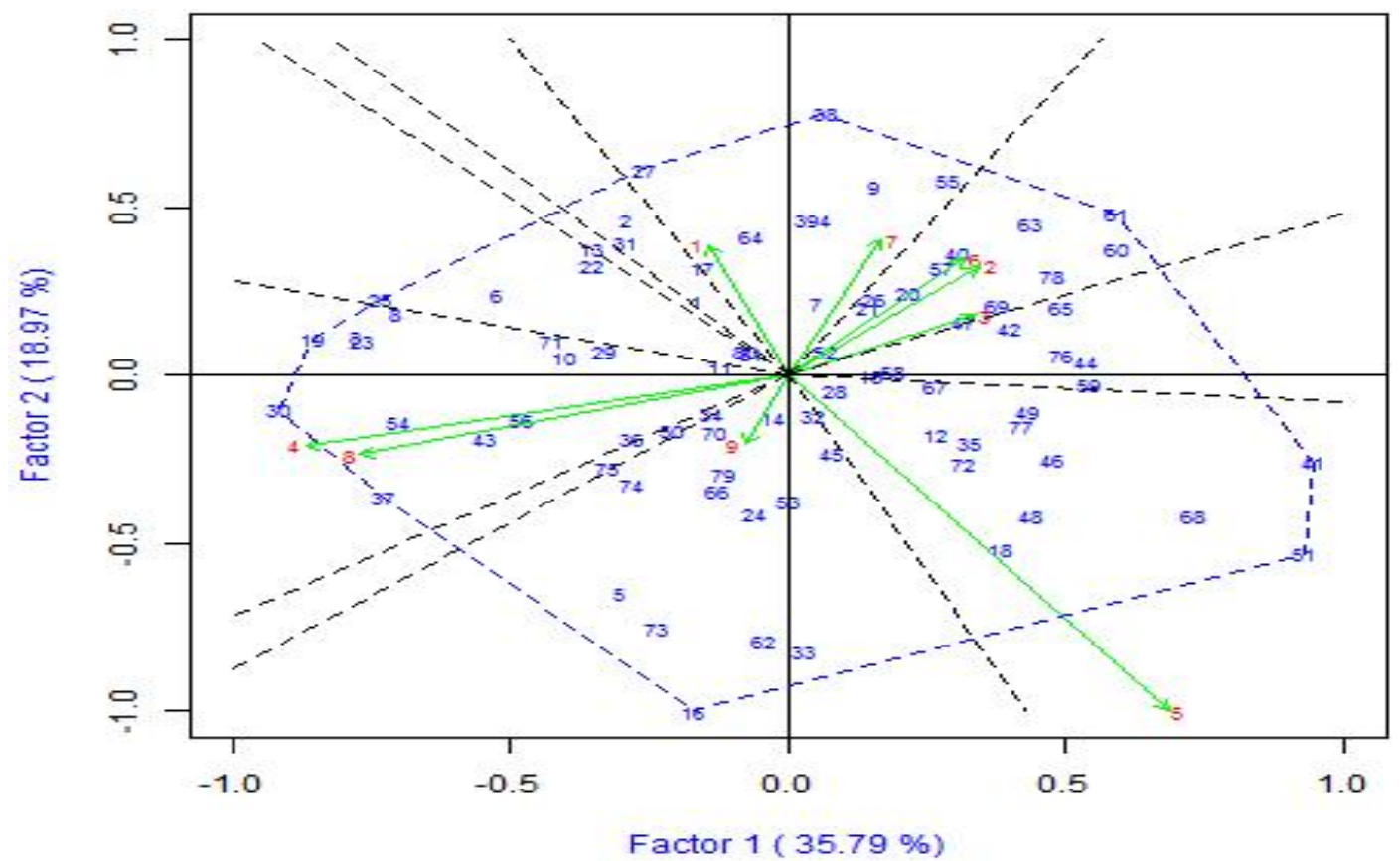

Fig 2. AMM2 biplot for grain yield of 81 wheat genotypes tested over nine environments

\section{DISCUSSION}

The ANOVA based on AMMI analysis revealed major role of GEI in total phenotypic expression of grain yield. This indicated that the performance and change in ranking of genotypes were mainly due to their interaction with the environments. The larger sum of squares of GEI indicated the significant response of genotypes over environments (Mohammad et al., 2011; Sabaghnia et al., 2008; Mohammadi et al., 2012). The GEI explained more than half of the total variation for grain yield, suggesting the existence of different sets of high yielding genotypes and mega-environments (Gauch and Zobel, 1996; Yan and Kang, 2003; Kadhem and Baktash, 2016). The AMMI model confirmed the intricate pattern of GEI and partitioned them into as many as eight IPCAs. However, the first two principal components amply explained the complex nature of GEI sum of squares. Abraha (2003) and Hagos and Abay (2013) confirmed that the first two IPCAs were sufficient to explain the GEI. Contrarily, Crossa et al. (1990) were of the opinion that AMMI with two, three or four IPCA are the best predictive model, 
while Misra et al. (2009) reported the significance of only first bilinear interaction term of the AMMI analysis.

Mean grain yield of nine environments were plotted against the scores of first principal component to give insights into complications posed by interaction due to genotype by environment. Environment E-02 was the most productive followed by E-03, E-06 and E-07. Environments E-01 and E-07 were declared as most stable due to their position in the proximity of $\mathrm{x}$-axis causing least fluctuations in the yield performance of genotypes. Environments E-04 and E-08 were the most discriminating as specified by their long distances from the x-axis. Among genotypes, G-79 surpassed all other genotypes as well as checks cultivars in yield and stability in most of the environments, thus, was declared as most stable and productive genotype.

The AMMI2 biplot is better in both fitness and accuracy for exploring the complex pattern of GEI. Principal component (PC) scores acquired through AMMI analysis for each genotype identify the stability of that genotype over environments. Genotypes having higher score of PC indicated their inconsistent performance and might have specific adaptation to certain environment. In the current experiment, G-11, G18, G-28, G-52 and G-58 were identified as widely adapted genotypes due to their position in the proximity of $\mathrm{x}$-axis in AMMI1 biplot. The AMMI2 model constructed based on IPCA1 and IPCA2 scores was better than AMMI1 because the first two principal components explained more variation of the total sum of squares of the GEI. Several researchers reported AMMI2 as better model than AMMI1 and AMMI3 to explore GEI (Crossa et al., 1990 and Gauch et al., 2008). Purchase et al. (2000) elucidated the inadequacy of AMMI3 biplot by plotting IPCA2 and IPCA3 scores, because higher axes are dominated by noise and have little projecting value.

Nine environmental vectors spread along four quadrants each representing single environment. The vectors shared the same quadrant indicated their similar response towards genotypes of that particular quadrant. Likewise, the widespread distribution of some genotypes along biplot showed the inconsistency of genotypes across the test environments. The long vector of E-05 indicated that this environment imposed enough pressure on genotypes to reveal their differences. In contrast, the short vectors of environments E-01, E-02, E-03, E-06, E07 and E-09 indicated their low discriminating power and hence, it could be inferred that less forces were applied on genotypes to diverge from mean yield in these environments ( $\operatorname{Rad}$ et al., 2013). Genotypes lying close with environment vectors showed that these genotypes had specific adaptation to these environments like G-01 to E-01, G-05 to E-02, G-26 to E-07 and G-72 to E-03 and E-06. Genotypes exhibited superior performance in particular environment hampers their use in other environments and hence, could be considered as specifically adapted (Tarakanovas and Ruzgas, 2006).

The AMMI stability values (ASVs) were calculated for genotypes to identify stable genotypes for grain yield. The ASV of G-79 was relatively low accompanied by higher mean yield and thus, appeared as high yielding and stable genotypes for grain yield. Stability in genotypes for grain yield using ASV in wheat across various environments was determined earlier by Desalegn et al. (2004), Ferney et al. (2006) and Purchase (1997) who reported the efficiency of ASV to rank genotypes according to their yield stability. Farshadfar et al. (2012) also advocated the use ASV technique to single-out wheat genotypes based on their grain yield stability. The AMMI analysis identified genotypes both for specific and wide adaptation. Based on stability and yield performance several genotypes were identified with superior performance than check cultivars. The wide spread distribution of environmental vectors shows lack of association among these environments. However, environments were clustered regardless of their geographical location which revealed unpredictable nature of agro-climatic conditions across four tested locations i.e. Peshawar, Charsadda, Nowshera and Swabi.

Conclusions: The AMMI analysis revealed major role of GEI in total phenotypic expressions of grain yield, indicating that the performance and ranking of genotypes were mainly due to their interaction with environments. The smaller sum of squares due to environments and genotypes suggested the lack of diversity in both environments and genotypes. Conversely, larger GEI sum of squares implied the existence of potential mega environments and inconsistency in performance which may lead to cross over interactions. Based on AMMI1 and AMMI2 biplots, none of the tested genotypes could be unanimously declared as stable and high yielding genotype based on all the traits. However, AMMI1 model declared G-79 as the most stable and high yielding genotype for grain yield Similarly, AMMI2 biplot declared G-58 as widely adaptable genotype for grain yield. Overall, G-79 was declared as the most stable and high yielding genotype and thus, needs further testing at national level before release as a new wheat variety.

\section{REFERENCES}

Abraha, A. 2003. Genotype by environment interaction of bread wheat genotypes under dryland growing conditions of Tigray. MSc. Thesis, Mekelle University, Ethiopia.

Crossa, J., G.H. Gauch andR.W. Zobel.1990. Additive main effects and multiplicative interaction analysis of two international maize cultivar trials. Crop Sci. 30: 493-500

Desalegn, D., S. Gelalcha, B. Yaie, B. Girma, B.Mamo 
and D. Masresha. 2004. Grain yield stability of bread wheat genotypes in favorable and stressed environments.76-85. Proceedings of the $12^{\text {th }}$ Regional Wheat Workshop for Eastern, Central and Southern Africa Nakuru, Kenya,22-26.

Farshadfar, E., R. Mohammadi, M. Aghaee and Z. Vaisi. 2012. GGE biplot analysis of genotype $\times$ environment interaction in wheat-barley disomic addition lines. Australian J. Crop Sci. 6 (6): 1074-1079.

Ferreira, D.F., C.G.B. Demétrio, A.A. Manly, Machado and R. Vencovsky. 2006. Statistical models in agriculture: biometrical methods for evaluating phenotypic stability in plant breeding. Cerne 12 : 373-388.

Ferney, G.H., M. Alexei and A. Aigul. 2006. Evaluation of grain yield stability, reliability and cultivar recommendations in spring wheat (Triticum aestivumL.) from Kazakhstan and Siberia. J. Central European Agric. 4: 649-660.

Gauch, H.G. 1992. Statistical Analysis of Regional Yield Trials: AMMI Analysis of Factorial Designs. Elsevier, Amsterdam. 278.

Gauch, H.G. and R.W. Zobel. 1997. Identifying megaenvironments and targeting genotypes. Crop Sci. 37:311-326.

Gauch, H.G., H. P. Piepho andP. Annicchiarico. 2008. Statistical analysis of yield trials by AMMI and GGE. Further considerations. Crop Sci. 48:866889.

Gauch, H.G. andR.W. Zobel.1996. AMMI analysis of yield trials. In Kang, M.S., Gauch, H.G. (ed.) Genotype by environment interaction. CRC Press, Boca Raton, FL.

GEA-R. 2015. Genotype $\times$ Environment Analysis with R for Windows, Version 4.0". http://hdl.handle.net/11529/10203 International Maize and Wheat Improvement Center.

Hagos, H.G. andF. Abay. 2013. AMMI and GGE biplot analysis of bread wheat genotypes in the Northern part of Ethiopia. J. Plant Breed. Genet., 12-18.

Kadhem, F.A. andF.Y. Baktash.2016. AMMI analysis of adaptability and yield stability of promising lines of bread wheat (Triticum aestivum L.). The Iraqi J. Agric. Sci. 47: (Special Issue): 35-43.

Misra, R.C., S. Das, M.C. Patnaik.2009. Ammi model analysis of stability and adaptability of late duration finger millet (Eleusine coracana) genotypes. World App. Sci. J. 6 (12): 16501654.

Mohammad, F., O.S. Abdalla, S. Rajaram, A. Yaljarouka, N.U. Khan, A.Z. Khan, S.K. Khalil, I.H. Khalil, I. Ahmad andS.A. Jadoon.2011. Additive main effect and multiplicative analysis of syntheticderived wheat under varying moisture regimes. Pakistan J.Bot. 43 (2): 1205-1210.

Mohammadi, M., R. Karimizadeh, N. Sabaghnia and M. K. Shefazadeh. 2012. Genotype $\times$ environment interaction and yield stability analysis of new improved bread wheat genotypes. Turkish J. Field Crop. 17 (1): 67-73.

Pacheco, Á., V. Mateo, A. Gregorio, R. Francisco, C. José and B. Juan. 2015. "GEA-R (Genotype $\times$ Environment Analysis with $\mathrm{R}$ for Windows) Version 4.1", hdl:11529/10203, CIMMYT Research Data \& Software Repository Network, V16

Purchase, J.L., H. Hatting andC.S. Vandeventer. 2000. Genotype $\times$ environment interaction of winter wheat (Triticum aestivum L.) in South Africa: Stability analysis of yield performance. South Afri. J. Plant Soil. 17: 101-107.

Purchase J.L. 1997. Parametric analysis to describe $\mathrm{G} \times \mathrm{E}$ interaction and yield stability in winter wheat. Ph.D. thesis. Dep. of Agronomy, Faculty of Agriculture, Univ. of the Orange Free State, Bloemfontein, South Africa.

Rad, N.M., M.A. Kadir, M.Y. Rafii, H.Z. Jaafar, M.R. Naghavi andF. Ahmadi. 2013. Genotype $\times$ environment interaction by AMMI and GGE biplot analysis in three consecutive generations of wheat (Triticum aestivum. L) under normal and drought stress conditions. Aust. J. Crop Sci. 7: 956-961.

Sabaghnia, N., S.H. Sabaghpour andH. Dehghani. 2008. The use of an AMMI model and its parameters to analyze yield stability in multi-environment trials. J. Agric. Sci. 146: 571-581.

Tarakanovas, P. andV. Ruzga.2006. Additive main effect and multiplicative interaction analysis of grain yield of wheat varieties in Lithuania. Agron. Res. 4:91-98.

Yan, W.and M.S. Kang.2003. GGE Biplot Analysis: A graphical tool for breeders, geneticists, and agronomists. CRC Press, Boca Raton, FL. 